\title{
Correction: Koh, L.B., et al. Epoxy Cross-Linked Collagen and Collagen-Laminin Peptide Hydrogels as Corneal Substitutes. J. Funct. Biomater. 2013, 4, 162-177
}

Li Buay Koh ${ }^{1, \dagger}$, Mohammad Mirazul Islam ${ }^{2,3, \dagger}$, Debbie Mitra ${ }^{4, \dagger}$, Christopher W. Noel ${ }^{4, \dagger}$, Kimberley Merrett ${ }^{3,4}$, Silvia Odorcic ${ }^{4}$, Per Fagerholm ${ }^{3}$, William Bruce Jackson ${ }^{4}$, Bo Liedberg ${ }^{5}$, Jaywant Phopase ${ }^{1, \dagger}$ and May Griffith ${ }^{2,3, \dagger}, *$

1 Integrative Regenerative Medicine Center, Department of Physics, Chemistry and Biology, Linköping University, SE 58183 Linköping, Sweden; E-Mails: mayko@ifm.liu.se (L.B.K.); jayph@ifm.liu.se (J.P.)

2 Swedish Nanoscience Center, Karolinska Institute, 17177 Stockholm, Sweden;

E-Mail: mohammad.islam@ki.se

3 Integrative Regenerative Medicine Center \& Department of Clinical and Experimental Medicine, Cell Biology Building, Linköping University, SE 58185 Linköping, Sweden;

E-Mails: kim.merrett@sympatico.ca (K.M.); per.fagerholm@liu.se (P.F.)

4 Ottawa Hospital Research Institute, University of Ottawa Eye Institute, 501 Smyth Rd. Ottawa,

ON K1H 8L6, Canada; E-Mails: debbiemitra@hotmail.com (D.M.);

christophernoe190@gmail.com (C.W.N.); silvia.odorcic@gmail.com (S.O.); bjackson@ohri.ca (W.B.J.)

5 Center for Biomimetic Sensor Science, Nanyang Technological University, Research Technoplaza, Story 6, 50 Nanyang Drive, Singapore 637553; E-Mail: bliedberg@ntu.edu.sg

$\dagger$ These authors contributed equally to this work.

* Author to whom correspondence should be addressed; E-Mail: may.griffith@liu.se.

Received: 11 March 2014 / Accepted: 12 March 2014 / Published: 17 March 2014

It has been brought to our attention very recently that we had an omission error in our methods section of the paper [1]. This is Section 3.4, which should have read as follows:

The tensile strength, Young's moduli and elongation at break of the $10 \%$ hydrogels were determined on an Instron electromechanical universal tester (Model 3342) equipped with Series IX/S software, using a crosshead speed of $10 \mathrm{~mm} \cdot \mathrm{min}^{-1}$ and a gauge length for testing of $5 \mathrm{~mm}$. Hydrogels 
with $0.55 \mathrm{~mm}$ thickness were equilibrated in PBS and cut into $10 \mathrm{~mm} \times 5 \mathrm{~mm}$ rectangular sheets. The load cell used was $10 \mathrm{~N}$.

For $18 \%$ hydrogels, measurements were made on an Instron universal test machine (Biopuls 3343, High Wycombe, UK). The measurements were carried out under water immersion at $37{ }^{\circ} \mathrm{C}$. Dumb-bell shaped hydrogels of $0.5 \mathrm{~mm}$ thickness were made for the mechanical properties measurement. The grip area at each end was $6 \mathrm{~mm} \times 10 \mathrm{~mm}$ with a gauge segment of $14 \mathrm{~mm} \times 6 \mathrm{~mm}$. The mechanical testing was carried out with the crosshead moving at a speed of $10 \mathrm{~mm} \cdot \mathrm{min}^{-1}$ and the load cell was $50 \mathrm{~N}$.

A minimum of three specimens was measured for each hydrogel formulation and repeated for three independent experiments.

\section{Reference}

1. Koh, L.B.; Islam, M.M.; Mitra, D.; Noel, C.W.; Merrett, K.; Odorcic, S.; Fagerholm, P.; Jackson, W.B.; Liedberg, B.; Phopase, J.; Griffith, M. Epoxy Cross-Linked Collagen and Collagen-Laminin Peptide Hydrogels as Corneal Substitutes. J. Funct. Biomater. 2013, 4, $162-177$.

(C) 2014 by the authors; licensee MDPI, Basel, Switzerland. This article is an open access article distributed under the terms and conditions of the Creative Commons Attribution license (http://creativecommons.org/licenses/by/3.0/). 